\title{
The Rhetorical and Conditional Interpretation of Site, with Examples from the Work of Berthold Lubetkin
}

\author{
ANDREW R. TRIPP \\ Texas A\&M University
}

This paper concerns the rhetorical interpretation of site in architecture. While my ultimate goal is to prompt alternatives to formalism in the beginning education of the architect, this paper presents the topic as a theoretical concern with examples from the work of Berthold Lubetkin. In particular, I will consider the topic of orientation as it relates to site definition in the Whipsnade House (1934-35) and the Penguin Pond (1933-34). These architectural projects introduce the possibility of establishing a rhetorical project alongside the critical project of Western Modernism, for which Hans-Georg Gadamer and David Summers will be my philosophical guides.

\section{THE WHIPSNADE HOUSE}

Two works by Lubetkin and the Tecton architectural partnership will serve as my introductory examples into the topic of orientation: The Whipsnade House (1934-35) and the Penguin Pond (1933-34).

The earliest surviving artifact related to the Whipsnade House is a topographic survey of the site made by J. L. Kier and Company and dated June $1934 .{ }^{1}$ In the margin of the blueprint, several small pencil sketches show the boundary of the proposed site platform along side a simple compass rose. As proposed, the platform observes two kinds of orientation, topographical and cardinal. It is both normal to the slope and directed due south. For these orientations to coincide and still satisfy the conditions of a right angle required some attention to site selection. Defining the site platform proceeded according to the determination of site orientation. Lubetkin himself confirmed the primary role of this topic: "Orientation," he wrote, "is the problem from which I would start."2

The configuration of the floor plan, which is typical of a weekend house, also shows concern for orientation. The bedrooms are located in the eastern quadrant of the plan, the living and dining rooms in the western, and the kitchen in the northern. ${ }^{3}$ Furthermore, Lubetkin studied daylighting for its visual contrast and relief; for example, photographs of the living room show the afternoon sun reflected and refracted by the horizontal panes of open windows. ${ }^{4}$

The photographs I have in mind are by Dell and Wainwright, ${ }^{5}$ who emphasized the orientation topic through their compositional approach to architectural photography. A photograph of the "sun-catcher" porch is characteristic of their work and illustrates my point. The seated woman is Margaret Church, who was an architect at Tecton at the time. ${ }^{6}$ Through the manipulation of the cavalier view, the frame, and the depth of field, the photographer represents Margaret as if she were perched precariously upon some long jetty. Her posture shows a degree of artifice as well. Her subtle twist recognizes two orientations-analogous to the site platform-the normal of the slope, and the direction of its southern aspect. Her pose is a variation on the contrapposto type, which, as David Summers has shown, is a visual emblem of rhetorical antithesis. ${ }^{7}$ In the photograph, Margaret is a rhetorical figure (a character) that indicates - through analogy - the antithesis of site orientations.

\section{THE PENGUIN POND}

The Penguin Pond at Regent's Park Zoo develops the orientation topic further. Again, a brief history is instructive. ${ }^{8}$

Plans for a new penguin enclose at the London Zoo began as early as September 1933. By this time, the Zoological Society of London (ZSL) had selected the existing Waders' Inclosure as the site of a new exhibit. The Waders' Inclosure was a small square of fenced-in ponds for waterfowl, located just between the Lion House to the north and the Tea House to the south. The Bird House and Aviaries were located toward the southeast, just beyond the Deer and Cattle grounds. In the opposite direction, toward the northwest, was the Raccoon Tree enclosure with the Antelope Paddock in the distance. The main attraction in this area of the zoo was the Lion House, which was a Victorian exhibition hall with open stadium seating on one side and a row of lion cages on the other. It had been opened with considerable fanfare in 1876, and as a sign of its prominence a bust of the first president of the ZSL, Sir Stamford Raffles, was mounted just inside the main entrance, which-being on the southern side of the building-opened up directly onto the Waders' Inclosure.

In January 1934, Lubetkin and Tecton presented their design of the new Penguin Pond to the ZSL, who enthusiastically approved its construction along with a significant increase in budget. All that survives of this four-month design phase is a single drawing and a handful of photographs of the model. ${ }^{9}$ The surviving drawing is a significant document because it reveals an attitude toward site that is no longer recognizable in the current setting of the built work. ${ }^{10}$ 
The sheet consists of a plan, elevation, and isometric drawing of an initial proposal (along the top of the sheet), as well as three plan sketches that likely come later. When envisioned in the existing setting of the Waders' Inclosure, the initial proposal shows a concern for directing the flow of visitors from out of the Lion House, past the Penguin Pond, and toward the Bird Houses and Aviaries beyond. The arrows shown in the isometric drawing are fragments of the ZSL's larger intention to arrange a circuit through the gardens that reenacted the classificatory order of the animal world, such as the ordered link between penguins and other birds. ${ }^{11}$ Two orientations are maintained throughout the project, one observing the typological order toward the birds (and away from the lions), ${ }^{12}$ and the other observing the cardinal directions. The spiraling ramps, much like Margaret's contrapposto in the photograph of the Whipsnade House, negotiate dramatically (and with extreme artifice) between these two orientations.

In this interpretation of the Penguin Pond, the site is not defined by metrical space or material context; rather, it is defined by the idea of decorum-by what is appropriate to the circumstances of the place. In these gardens, it is appropriate to extend and contract in relation to the zoological order of the animals. Lubetkin has said that his intention was to display the unique talents and capabilities of the penguins by roviding them with a circuitous theater. Penguins have different capabilities than lions, and this Promethean contrast (or proportion) is on display as well. ${ }^{13}$ However, the notion that the site of the Penguin Pond was defined by the decorum of the circumstances does not limit the project to the place as it was; indeed, an important part of the project was to imagine the site as what it should be. A small but important note on the drawing says that the length of the enclosure should be "not less than 50 ', poss [ibly] more." Indeed, while the initial proposal limited the extent of the site to the existing Waders' Inclosure, the final project was nearly thirty feet longer in the northwest direction.

\section{GADAMER AND THE RHETORICAL}

Decorum is an ancient architectural term as well as a principle of classical rhetoric. Insofar as the Penguin Pond takes into account the circumstances of the place in order to persuade the development of that place into a version of what should be, then the project is also an exemplary demonstration of rhetorical thinking. My appeal to rhetorical thinking is in its potential to oppose critical (and historical) method. This claim requires some brief philosophical preparation.

In the first chapter of Truth and Method (2006), Hans-Georg Gadamer acknowledges a precursor in Giambattista Vico, the $18^{\text {th }}$ century Italian philosopher and professor of rhetoric. ${ }^{14}$ Vico, writes Gadamer, sounds a "critical note directed against the theoretical speculations of the philosophers [that] can be heard in the Roman concept of the sensus communis; and that note Vico sounds again from his different position of opposition to modern science (the critica)." In Gadamer's interpretation of Vico, which I take to be sound, sensus communis is not "common sense" as we understand it, as an abstract and universal mental faculty within each of us (ala. Emmanuel Kant); rather, it is the "concrete universality represented by the community of a group." Sensus communis refers to the sense that permits agreement and "founds community." Gadamer positions Vico's sensus communis in the context of the ancient distinction between sophia (theoretical knowledge) and phronesis (practical knowledge). "Practical knowledge, [or] phronesis" Gadamer writes, "is another kind of knowledge. Primarily, this means that it is directed towards the concrete situation. Thus it must grasp the 'circumstances' in the infinite variety." Vico acknowledging the importance of phronesis when he appeals to the rhetorical canon-and especially to eloquence (saying the right thing) and prudence (knowing the right thing to do) -as necessary components in training a robust sensus communis. The rhetorical is opposed to the critical insofar as it concerns determining, saying, and doing what should be (right or correct) in concrete circumstances.

\section{SUMMERS AND THE CONDITIONAL}

More recently, in his book Real Spaces: World Art History and the Rise of Western Modernism (2003), David summers takes up and operationalizes the notions of the sensus communis and rhetorical understanding. In direct opposition to formalist art interpretation, Summers pursues what he calls a conditional understanding of the work of art in its spatial context. The term 'condition', originally from discipline of law (and rhetoric), carries the sense of a contract or an agreement: I will do this on the condition that you will do that. The meaning of its Latin root, 'dicere', is 'to show' or 'to indicate' and therefore 'to point to' by means of language. A condition is a stipulation that makes an agreement possible. Conditions hold together things that are otherwise apart. They are necessary for the creation of community.

As he describes it, orientation is a particularly potent condition. In language, as we all know, the term is derived from the Latin word for 'east', 'oriens', from the verb 'orior', meaning 'to rise' or 'to appear', but which in another sense also means 'to flow', 'to move', or 'to run', as in a course, or a river (i.e., the Rhine in Germany). We associate the term with a deep sense of beginning and rebirth, and therefore with knowing one's place and finding one's way. It is perhaps because of these associations that we use the term 'orientation' as a substitute for any "proper spatial relation to things and other people in the world." ${ }^{15} \mathrm{We}$ call ourselves properly 'oriented' when we know where to go, what to do, or how to behave among others; and we are 'disoriented' when such things are unknown. Insofar as we choose to face or align with one direction or another, orientation can "entail values and polarities of values." ${ }^{16}$ In the most general way, we might ask "With what should we align ourselves? What should we face?" Alternatively, as architects we might ask "With what should this building align? What should it face?" 
According to Summers, orientation, or more generally, alignment and facing, is a condition of social space. Consider a horizontal platform, what Alberti calls an area, "a certain, particular plot of land to be enclosed."17 Such an area may present any number of potential alignments with its larger surroundings. Summers writes that:

Our actual facing presupposes some relation to a more or less limited area, and that area has the potential to be a definite place, in some relation to the implicitly indefinite world at large. Insideness, outsideness and some right, 'facing' relation between the two are conditions of social space before it has been specified as one social space or another. When such specification takes place, then our facing may also become a culturally specific 'course of action'. If a clearing has an upright stone opposite the side on which we enter, then the floor not only has an internal alignment, it also directs our attention, movement, and actions. The alignment or external orientation of a place, which may further shape our facing, may be further determined by something of importance outside of the place itself, a mountain, for example, or the rising sun. In this way, literally by means of a social space, our alignment is made part of a larger embracing order, part of a cosmos. ${ }^{18}$

A whole anthropology of ritual alignments is available to the patient scholar. Cultures that bury their dead will often align the body in "right" or "proper" relations with a larger embracing order. In ancient Egyptian burials, the dead were laid on their sides facing west. Early Christians were aligned to the east. Some cultures sought topographical rather than cardinal alignments; others saw a need for further distinctions. In northern Canada, some Inuit men were laid facing the sea, with women facing the land.

In an aboveground ritual setting, an example of this condition is the Sacred Rock at Machu Picchu, where an elevated rectangular area flanked by two structures is concluded on one end with an upright stone that was honed and cut to the precise profile of Mt. Yanantin in the distant background. The alignment of the mountain, the stone, and the opposite and open edge of the area defines a positioning around which the meaning of the space is structured. Entering the area, we can image how we align with the mountain by facing the stone. Nevertheless, the stone only appears as a profile or outline of the mountain on the condition of orientation. Often, the mountain in the distance is obscured by weather, but the stone remains in its position as a substitute, a re-presentation of what is known but otherwise unseen.

Vitruvius considered orientation to be a fundamental dimension of architectural ordering. ${ }^{19} \mathrm{He}$ advised architects to direct certain parts of cities and houses toward the east to promote health and convenience; ${ }^{20}$ but he had different intentions in the plan of sacred sites. ${ }^{21}$ Again, the interpretation of orientation is conditional; sacred statues, he writes, "seem to come-forth... and gaze back upon those praying" on the condition that the supplicant and shrine are aligned with the statue and sun. Vitruvius's interpretation of orientation in sacred settings was concerned with structuring an agreement with an unseen other-the benevolent gaze of the gods (deorum inmortalium)-and the pious gaze of man. ${ }^{22}$

Changes in alignment or culture accentuate the importance of orientation. Consider the case of the Acropolis, razed by the Persians, then later rebuilt after the Athenian victory with a second Classical Propylaia constructed along a new alignment framing the site of the Battle of Salamis in the distance. Consider Michelangelo's renovation of the Capitoline Hill and the realignment of the elevated platform away from the ancient and mediaeval city and toward the Vatican and the new Renaissance city. In such cases, the change of alignment becomes the bearer of new meaning, a promise, but this promise is not always benign. For example, consider the case of the Aztec Temple Mayor. The fabric of the precolonial city was aligned east-to-west facing the most prominent temples, but when the Cathedral of Mexico City was built, the fabric was transformed to observe a north-to-south orientation. So powerful was the meaning of the pre-existing alignment that the colonists denied a conventional westwerk on the cathedral in order to avoid equivocation.

\section{THE SITING OF THE BOURSE}

As a recording of culture, orientation is wrapped up in our recounting. Lubetkin was fond of recounting architectural principles as narratives. Like many architects, it was as a storyteller and not a scientist that he discussed the ethical conflicts that he confronted in the course of contemplating architecture. There is one story in particular that he often repeated, and which is relevant to our topic. ${ }^{23}$

In the years before the Russian Revolution, while still a young boy in St. Petersburg, Lubetkin occasionally celebrated holidays with a carriage ride through the historic center of the city. An older family friend, Mikhail Dubinsky, provided the transportation and conversation. ${ }^{24}$ On one such occasion, their discussion turned to the plan of the St. Petersburg Stock Exchange on the western spit of Vasilevsky Island, just across the Bolshaya Neva River from the Winter Palace.

The plan of the new Exchange building was an issue of some debate in the late eighteenth-century, which Dubinsky rehearsed to Lubetkin.

In 1782, at the request of Ekaterina II, the Italian Baroque architect Giacomo Quarenghi proposed a plan that positioned the front elevation of the Exchange along the southern edge of the island directly facing the Winter Palace across the river. For Quarenghi, the boundary and character of the 
site was defined by the "already existing chain of the builtup embankment," of which the Exchange was to conform as "one of the links." ${ }^{25}$ Construction had already begun when Quarenghi's design suffered harsh criticism from Voltaire and the Tsarina, who ordered the Exchange be demolished and rebuilt according to a new plan by the French Neoclassical architect Thomas de Thomon. De Thomon's plan, owing more to Laugier than Quarenghi, called for a "magnificent autonomous mass, flanked by wide gaps on the two sides, as though to heighten its monumentality." Nevertheless, while the plan of the new building was pulled away from the circumstantial boundaries of Vasilevsky Island, it was also dramatically reoriented to align with the rush of the oncoming Neva River. De Thomon's design of the building presumed the idea of a site defined not by its material "context," but rather by a formal symmetry across a northwesterly axis extending endlessly into space. This axis, aligned as it was with the visible forces of nature, had the added feature of balancing the Winter Palace on the one side with the Peter and Paul Fortress on the other, transforming their relative position within the urban hierarchy, and creating a "vast, flowing, indeterminate ensemble of open space."

After describing these events, Dubinsky asked the much younger Lubetkin: "Now, if you were the architect and had to decide about the alignment of the new design, would you center it on the Winter Palace or on the mighty flow of the Neva?" With what should the building align? What should it face? What should be its orientation? Lubetkin recalls pondering the question for some time before answering decisively that the plan of the new exchange building ought to have been "purely circular" in order to face all of the possible orientations, including those immediately across the river and those extending along its flow. When Dubinsky heard this response, he exclaimed, "Now we have among us a future architect!"

The story illustrates Lubetkin's interest in avoiding what he called a "decisive classification," which is to say, avoiding a dogmatic commitment to any abstract principle. The orientation of the Exchange could be astral or zodiacal, but this would not be appropriate to its civic role as a measure of commerce. It could be cardinal or solar, and in that way acknowledge the importance of organizing the interior, but again, the question was posed not in terms of access to resources, but in terms of civic decorum. The example of an orientation aligned with the flow of the river suggests a topographical possibility as well, but in this case, it is important to remember that the river is also the mythological origin of the city. Should the Exchange be oriented to the mythological origin of the city in the river or the historical source of social power in the palace? Lubetkin's response belies his suspicion or displeasure with this division, and suggests that he saw no need to exclude the possibility of multiple orientations, depending on what's appropriate in the circumstances.

\section{ENDNOTES}

1 "Mr. Lubetkin's Site," blueline print with pencil sketches in the margin, June 1934, RIBA Archive PA117/1.

2 B. Lubetkin, "Diary from Peterlee Newtown," January 9, 1948, RIBA Archive LUB/15/20/1-2.

3 There is no evidence that Lubetkin ever diagrammed the path of the sun or that he used such diagrams to inform the configuration of the Whipsnade House.

4 Ernö Goldfinger would later insist that such horizontal surfaces were "photobolic screens" intended to bounce light off the ceiling and farther into the interior depths of a building, but the effect that is captured in the photographs of the Whipsnade House is not so much the extension of daylighting as the creation of disorientation.

5 The architectural photographers for the Architectural Review.

6 She would soon marry Berthold Lubetkin.

7 D. Summers, "Contrapposto: Style and Meaning in Renaissance Art," The Art Bulletin 59, no. 3 (September 1977): 336-361.

8 A brief history of the project for the Penguin Pond is useful in ameliorating the gap between its history and its renown. A separate review of the history of interpreting the project would make for an interesting study. For example, the project is occasionally considered the centerpiece of the partnership between the disciplines of engineering and architecture; or the evidence of the diffusion or decay-depending on the relative degree of eclecticism that is interpreted in the work-of international rationalism and constructivism; or the transformation of subjectivity and the focus on childhood; or-again depending on one's apologetics-the target or aegis of ecological, material, technological or social criticisms. It is only rarely considered an example of zoological architecture, which suggests that for its type, it is neither wholly exceptional nor wholly distinguishable. In the contemporary period, architects who visited London and the Zoo at Regent's Park were impressed by the Gorilla House and the Penguin Pond, but they were rarely impressed by both; the selection of one over the other says as much about the selector as it does the work.

9 The primary medium of design development was not drawing or diagramming, but rather, three-dimensional models made of cardboard. Lubetkin admitted so much in a 1989 letter to the Architects' Journal, and Tecton assistant William Tatton-Brown recalled the same thing in an interview with Louise Brodie in 1996.

10 Similar to the Whipsnade House site survey, this early drawing records an early conversation, this time between Lubetkin and Geoffrey Vevers, the superintendent of works at the ZSL. The drawing precedes Ove Arup's involvement in the project.

11 This is evident in contemporaneous maps of the Zoo.

12 In the final plan, the ramps are rotated to face north and south, however, a fullheight wall is located on the north side, as if to arrest any direct communication between penguin's and predators.

13 The display of a unique talent contains more than a hint of the Promethean myth in which capabilities are handed-out to all the animals in different proportions.

14 H.-G. Gadamer, Truth and Method, second, revised edition (London: Continuum, 2006), 19-20.

15 D. Summers, Real Spaces: World Art History and the Rise of Western Modernism (New York: Phaidon Press, 181).

16 Summers, 181.

17 Leon Battista Alberti, On the Art of Building in Ten Books, trans., Joseph Rykwert, Neil Leach, and Robert Tavernor (Cambridge, MA: The MIT Press, 1989), 8.

18 Summers, Real Spaces, 182-3.

19 In my interpretation of Vitruvius's text, I have adjusted existing translations of the Latin using the transcription of the British Museum's Harleian 2767 manuscript published in Frank Granger's translation of Vitruvius On Architecture (Cambridge, MA: Harvard University Press, 1931; 1998). For guidance, I have turned to Ingrid D. Rowland's recent translation of Vitruvius: Ten Books on Architecture (Cambridge, UK: Cambridge University Press, 1999), as well as those passages most expertly translated in Indra Kagis McEwen's Vitruvius: Writing the Body of Architecture (Cambridge, MA: The MIT Press, 2003).

20 According to Vitruvius, in the plan of the city, the architect should avoid the alignment of marshes and winds arising from the east, see: Vitruvius 1.4.1, 1.4.11, and 8.2.3. Then, in the plan of the house, the east is the most appropriate position for private bedrooms, libraries, dining rooms, and mangers, see: Vitruvius 1.2.7, 6.4.1-2, 6.6.1, 6.6.5, and 6.7.3.

21 Vitruvius 4.5.1. English translation adjusted from McEwen (2003), 173. "This is how to determine which regions of the sky the sacred houses (aedes sacrae) of the immortal gods should observe (spectare). If no reason stands in the way, and given the unrestricted power to do so, both the house (aedis) and the statue placed in the cella are to look toward the evening region of the sky, so that a person approaching the altar to make offerings or sacrifices looks to the part of the sky where the sun rises and also at the statue in the temple. In this way, when people undertake vows they will gaze at once upon the temple, on the sun rising in the eastern sky (oriens), and on the statues (simulacra) themselves that seem to come-forth (exorientia) along with the sun and gaze back upon those praying 
and making sacrifices - which obviously demands that all the altars of the gods face east." It is important to note that the term simulacrum, translated above as 'statue', can- and perhaps should- be understood in relation to its wider significance as 'image' or even more generally as 'representation'. In De architectura, the context of the term simulacrum suggests several different meanings. On several occasions, Vitruvius uses the term to refer to sacred statues of specific deities, see: Vitruvius 1.1.6, 2.9.13, 7.5.2, and 9.P.16. Elsewhere he uses the term to refer to sacred statues in general and the architectural adjustments required to accommodate the approach toward them, see: Vitruvius 4.3.4, 4.3.8, and 4.9.1. The notion that heavenly representations arise rather than rise (exoriri rather than oriri) is repeated by Vitruvius only in his discussion in book nine of the sun's course through the zodiac, in which the term simulacrum takes on the meaning of 'constellation'. See: Vitruvius 9.3.1, 9.4.2-3, 9.4.6, and 9.5.1. In this celestial context, he is referring to the astronomical poem Phaenomena by Aratus of Soli, who he cites and likely knew through Cicero's translation, Vitruvius 9.6.3, as well as to the related tradition of "synchronic risings and settings" in which heavenly bodies drag each other along their course. On astronomy, see: Vitruvius 1.1.10, and 9.7.3.

22 McEwen has made a compelling case that, while this passage does not accurately report on Greek or Hellenistic temple layouts, it does reflect the tradition of Imperial Roman temples that follow from the Temple of Divus Julius built on the eastern end of the Forum Romanum and dedicated to Julius Caesar in 29 BCE, see: McEwen (2003), 174.

23 This tale is included in both Lubetkin's Samizdat and Memoirs manuscripts, and both his daughter Sasha and her husband John recall the significant number of times this tale was told to visitors.

24 Lubetkin uses only the name Dubinsky, which refers most likely to Mikhail Khaimovich Dubinsky (1877-?), who graduated from the Imperial Academy of Art in St. Petersburg in 1904, designed the Nikolayevskaya Naval Academy and a series of residences from 1910-11, including work on the former Baryantinsky family mansion on Sergievskaya Street (today 46-48 Tchaikovskogo Street) in St. Petersburg (Kravtsov).

25 Lubetkin, unpublished manuscript on Russian architecture (undated) (LUB/20/8/4/5-6). 